\title{
OBSTÁCULOS PARA A EFETIVIDADE DA TUTELA DE DIREITOS TRANSINDIVIDUAIS POR ENTIDADES SINDICAIS EM PREJUÍZO AO EFETIVO ACESSO À JUSTIÇA
}

\author{
Raíssa Fabris de Souza ${ }^{1}$ \\ Luiz Fernando Bellinetti ${ }^{2}$
}

\section{RESUMO:}

A tutela de direitos transindividuais por entidades sindicais constitui uma das dimensões do princípio do acesso à justiça previsto no art. $5^{\circ} \mathrm{XXXV}, \mathrm{CF} / 1988$, indispensável para a concretização de direitos fundamentais mínimos de uma coletividade. Entretanto, sua efetividade esbarra em diversas barreiras, sejam elas de âmbito global, oriundo de fenômenos como a globalização, consolidação do capitalismo e novas formas de produção, ou de âmbito local, vez que residem diversos resquícios de um modelo corporativista implementado na era Vargas. Estes obstáculos serão analisados detidamente no presente artigo, mediante a utilização do método dedutivo na pesquisa.

Palavras-chave: Acesso à justiça. Sindicatos. Direitos metaindiviuais. Obstáculos. Representatividade.

\section{OBSTACLES FOR THE EFFECTIVENESS OF THE PROTECTION OF TRANS- DIVIDUAL RIGHTS BY TRADE UNIONS IN DISRESPECT OF THE EFFECTIVE ACCESS TO JUSTICE}

\begin{abstract}
:
The protection of transindividual rights by trade union entities is one of the dimensions of the principle of access to justice established in art. $5^{\circ} \mathrm{XXXV}, \mathrm{CF} / 1988$, indispensable for the realization of the minimum fundamental rights of collectivity. However, its effectiveness comes up against several barriers, whether they are of a global scope, coming from phenomena such as globalization, consolidation of capitalism and new forms of production, or local scope, since there reside several remnants of corporatist model implemented in the Vargas era. These obstacles will be analyzed in this article, using the deductive method in the research.
\end{abstract}

Keywords: Access to justice. Unions. Metaindiviral rights. Obstacles. Representativity

\section{INTRODUÇÃO}

\footnotetext{
${ }^{1}$ Aluna do Programa de Mestrado em Direito Negocial na Universidade Estadual de Londrina. Bolsista CAPES/CNPq. Pós-graduada em Direito Constitucional Contemporâneo pela Universidade Norte do Paraná (UENP). Graduada pela Pontifícia Universidade Católica de Londrina - PUCPR. Advogada. Email: raissa_fabris_@hotmail.com

2 Possui graduação em Direito pela Universidade Estadual de Londrina (1980), mestrado em Direito das Relações Sociais pela Universidade Estadual de Londrina (1985) e doutorado em Direito pela Pontifícia Universidade Católica de São Paulo (1997). Atualmente é professor associado da Universidade Estadual de Londrina. Email: luizbel@uol.com.br
} 
As demandas coletivas, surgidas com o advento da globalização e com o avanço do capitalismo, constituem medidas que visam precipuamente conferir um pleno acesso à justiça a uma coletividade ou a um grupo de pessoas. Inicialmente entendida como o direito ao ingresso de uma demanda no poder judiciário, atualmente o acesso à justiça se trata de um direito fundamental mais amplo, garantindo-se o direito a uma tutela adequada, justa e de acordo com as peculiaridades do direito material vindicado.

Neste viés, atualmente fala-se na observância do devido processo social, caracterizado pela dimensão coletiva do princípio do devido processo legal (art. $5^{\circ}$, LIV, $\mathrm{CF} / 88$ ), que possui como finalidade a desburocratização do processo e o afastamento do formalismo para, mediante a instituição de novas regras e princípios, ser alcançada a efetividade de um processo metaindividual e a justiça social.

Considerando a relevância dos direitos tutelados, bem como a previsão legal da eficácia erga omnes ou ultra partes da decisão proferida no âmbito do processo (art. 103, CDC), capazes de resultar impactos para um número considerável de pessoas, o microssistema processual de tutela coletiva atribuiu expressamente a legitimidade a diversas entidades, previstas expressamente no ordenamento jurídico (ope legis).

O presente artigo iniciará com uma análise acerca da natureza jurídica e a classificação da legitimidade para a tutela de direitos metaindividuais, passando pelo caso específico das associações que devem cumprir um requisito objetivo (constituição prévia de 01 (um) ano, no mínimo) e um subjetivo (pertinência temática). Efetivar-se-á a diferenciação de pertinência temática com a representatividade adequada oriunda das class actions do direito estadunidense, bem como a possibilidade de sua análise pelas instâncias judiciais brasileiras.

Após, passa-se a expor obstáculos para a efetividade da tutela de direitos transindividuais por entidades sindicais, partindo de uma análise do sindicalismo em nível global, para uma análise do ordenamento jurídico interno. Analisa-se desde o histórico do sindicalismo até as recentes alterações legislativas implementadas pela Reforma Trabalhista e pela Medida Provisória n. 873, de $1^{\text {o }}$ de março de 2019, fatos que refletem diretamente na legítima representatividade dessas entidades em âmbito brasileiro.

Para tanto, utilizar-se-á o método dedutivo vez que, a partir de premissas iniciais e gerais visa-se chegar ao particular, mediante conhecimento dos pontos específicos da crise de 
representatividade no sistema sindical brasileiro, em prejuízo ao efetivo acesso à justiça e ao patamar civilizatório mínimo dos trabalhadores.

\section{O PROCESSO COLETIVO COMO INSTRUMENTO DE CONCRETIZAÇÃO DO ACESSO À JUSTIÇA}

O Estado Democrático de Direito possui como fundamentos o princípio democrático e o valor justiça visando o respeito, a proteção e promoção de direitos fundamentais. Além de uma tutela preventiva e repressiva efetivada individualmente, garante-se uma proteção à coletividade, surgindo uma nova perspectiva de atividade jurisdicional.

O direito à justiça constitui uma preocupação desde os primórdios da Magna Carta instituída pelo rei João Sem Terra, na Inglaterra, em 1215. O art. 40 do referido diploma afirmava que "a ninguém venderemos, a ninguém negaremos ou retardaremos direito a justiça”.

Este pode ser compreendido como o direito à convivência em uma sociedade em que o direito é realizado de forma concreta, seja diante da manifestação do poder judiciário como órgão estatal, seja mediante a implementação de políticas públicas efetivadas pelo poder executivo ou a implementação legal realizada pelo poder legislativo. Efetivar-se-á uma sociedade democrática e justa, prestigiando os direitos fundamentais e a dignidade humana (RAMOS, 2000, p. 38-39).

Historicamente a vertente do acesso à justiça passou por uma fase de afirmação no ordenamento jurídico brasileiro, sendo entendida em momentos pretéritos como o direito ao simples acesso ao poder judiciário, o que era obstaculizado por barreiras econômicas, socioculturais e até mesmo psicológicas.

Alternativas para a transgressão das referidas barreiras foram trazidas por Mauro Cappelletti e Bryant Garth (1988, p. 31) que introduziram doutrinariamente três ondas renovatórias de acesso à justiça:

Tendo início em 1965, estes posicionamentos emergiram mais ou menos em sequência cronológica. Podemos afirmar que a primeira solução para o acesso - a primeira 'onda' desse movimento novo - foi a assistência judiciária; a segunda dizia respeito às reformas tendentes a proporcionar representação jurídica para os interesses 'difusos', especialmente nas áreas da proteção ambiental e do consumidor; e o terceiro - e mais recente - é o 
que nos propomos a chamar simplesmente 'enfoque de acesso à justiça' porque inclui os posicionamentos anteriores, mas vai muito além deles, representando, dessa forma, uma tentativa de atacar as barreiras ao acesso de modo mais articulado e compreensivo.

Entretanto, como fruto de reivindicações por formas efetivas e céleres de justiça, contemporaneamente o direito ao acesso à justiça engloba não apenas a facilidade de ingresso no poder judiciário, mas o direito a uma tutela jurisdicional justa, efetiva, e condizente com o direito material vindicado.

Denota-se que a adequação da tutela processual ao direito material requerido pelo autor da demanda assume especial importância para o acesso à justiça das coletividades, o que se verifica quando da tutela pelos órgãos legitimados de direitos difusos, coletivos e individuais homogêneos (art. 81, CDC).

Segundo Ronaldo Lima dos Santos (2014, p. 238), "a noção de direitos coletivos surgiu para garantir o acesso à justiça a grupos sociais e a ocorrências ou situações que antes não encontravam guarida no Poder Judiciário”. Segundo o autor, aponta-se como antecedente da moderna ação coletiva o Bill of Peace inglês, do século XVII:

[...] tratava de uma autorização para o processamento de uma ação individual sob a forma coletiva, concedida nas hipóteses em que o autor requeria que o provimento da demanda englobasse os direitos de todos os indivíduos que estivessem em igual condição de litígio, para que a questão fosse tratada de modo uniforme e com vistas a evitar a multiplicação de processos.

Por intermédio das demandas coletivas amplifica-se o acesso à justiça de uma coletividade indeterminada ou um grupo determinado de pessoas. Aponta-se como benefícios dessas ações a socialização e democratização do processo, com a concretização de direitos e a alteração da realidade social; a possibilidade de correção de um ilícito que não seria postulado em uma demanda individual diante de seu ínfimo valor particular, mas que coletivamente possui um grande impacto social; a igualdade entre os litigantes; a molecularização da demanda e concretização do princípio da segurança jurídica e confiança legítima diante de decisões uniformes para casos similares; a redução de demandas no poder judiciário, dentre muitos outros. No âmbito trabalhista verifica-se pela importância da despersonalização da demanda por intermédio das ações coletivas diante da subordinação inerente à relação de trabalho. 
Nesta senda, aponta-se também o princípio da universalidade da jurisdição coletiva. Segundo este princípio, o processo coletivo constitui uma das formas mais eficazes de oportunidade que as massas possuem de acessar os novos canais de acesso à justiça, já que o processo individual ou atomizado traria diversos percalços. Removem-se obstáculos ao acesso à ordem jurídica justa com as ações moleculares atingindo o maior número possível de pessoas que tiveram seus direitos lesados (ENOQUE, 2018, p. 12).

Destaca-se que a Constituição da República de 1988 trouxe inúmeras inovações quanto ao regramento da tutela coletiva, dentre eles o tratamento da Ação Civil Pública no art. 129, III, como instrumento de defesa dos interesses coletivos, em sentido lato sensu, e a outorga da legitimidade de entidades associativas e sindicais para a defesa de interesses de seus associados e filiados. Nestes termos, art. $5^{\circ}$, XXI e $8^{\circ}$, III, da Carta Constitucional.

\section{DAS TEORIAS ACERCA DA LEGITIMIDADE DAS ENTIDADES SINDICAIS PARA A PROPOSITURA DAS AÇÕES COLETIVAS}

Com a finalidade de concretização do princípio do acesso à justiça é facultado a todos o direito de provocar o poder judiciário para a satisfação de direitos ou interesses. No entanto, em âmbito processual, deve-se verificar o que a doutrina denomina de "legitimidade ad causam".

Segundo Fredie Didier Jr. (2015, p. 343), para admissibilidade de uma demanda, deve-se identificar seu elemento subjetivo, sendo necessário que os sujeitos processuais estejam em determinada situação jurídica que lhes autorize a conduzir o processo em que se discuta aquela situação jurídica de direito material. Parte processual é aquela em que sua situação legitimadora decorre de certa previsão em lei, relativamente àquela pessoa e perante o respectivo objeto litigioso.

Em regra, a legitimação no direito brasileiro é ordinária, coincidindo "as figuras das partes com os polos da relação jurídica, material ou processual, real ou apenas afirmada, retratada no pedido inicial" (ARMELIN, 1979, p. 117). No entanto, aponta-se também a possibilidade de legitimação extraordinária, decorrente do art. 18 do CPC/15, pleiteando o autor da ação, em nome próprio, direitos de outrem.

É exatamente o que ocorre no sistema para a tutela de direitos e interesses coletivos. O microssistema processual coletivo conferiu legitimidade a entes expressamente previstos na 
legislação para a tutela de direitos difusos, coletivos e individuais homogêneos (art. 81, CDC).

Ainda que haja dissenso na doutrina, havendo corrente que aponte ser a legitimação ordinária autônoma ou anômala ${ }^{3}$, fato é que o direito material objeto da demanda não pertence ao autor da ação coletiva, mas pode beneficiar pessoas determinadas ou indetermináveis, ou seja, terceiros que não fazem parte da relação processual, caracterizando-se uma forma extraordinária de legitimidade (DINAMARCO, 2001, p. 205).

Além disso, poderá ser classificada também como exclusiva, pertencente apenas àqueles entes previstos na legislação, ressalvado o caso específico da ação popular em que a legitimidade é conferida a qualquer cidadão brasileiro (art. $5^{\circ}$, LXXIII, CR/88 e art. $1^{\circ}$, Lei 4.717/65); concorrente, havendo a possibilidade de qualquer um dos entes ajuizarem a ação, sem qualquer ordem preferencial; e disjuntiva, não dependendo da anuência ou autorização dos demais co-legitimados (DIDIER JR., 2015, p. 344-346).

Assim, o processo coletivo brasileiro efetivou no direito positivo a adoção de um regime de legitimidade extraordinária ope legis, havendo expressa autorização legal para que o ente defenda interesses coletivos no ordenamento jurídico. A título exemplificativo apontase o art. $5^{\circ}$ da Lei 7.347/83 que dispõe sobre a Ação Civil Pública.

No entanto, verifica-se, na prática, a adoção pelo regime ope legis não ocorre de forma plena e estanque. Em alguns casos específicos, exige-se uma identidade entre as finalidades institucionais do autor da ação e a temática tratada na ação coletiva. É o que ocorre no caso de associações, incluídas as entidades sindicais.

Para essas entidades exige-se a observância de um critério objetivo e um critério subjetivo. O primeiro relaciona-se à existência de pré-constituição há pelo menos 01 (um) ano da data do ajuizamento da ação, e o segundo exige a denominada pertinência temática. A causa de pedir e os pedidos efetivados na ação coletiva devem possuir relação com as finalidades institucionais do ente, como, no caso da Ação Civil Pública, a proteção ao meio ambiente, ao consumidor, à ordem econômica, à livre concorrência ou ao patrimônio artístico, estético, histórico, turístico e paisagístico (art. 5, V, “b”, Lei 7.347/1985).

Ressalte-se que o modelo brasileiro difere do modelo estadunidense (class actions), vez que neste a legitimidade é conferida aos indivíduos, para que exerçam a representatividade adequada da coletividade, examinada pelo juiz em cada caso concreto.

\footnotetext{
${ }^{3}$ Hipótese que não se confunde com a substituição processual ou representação.
} 
Trata-se da legitimidade ope judicis. Aqui no Brasil o autor configura um representante institucional previsto em abstrato pelo legislador (DINAMARCO, 2001, p. 201).

Pedro da Silva Dinamarco (2001, p. 202) faz a diferenciação entre pertinência temática e representatividade adequada, nos seguintes termos:

[...] esse requisito nada tem que ver com a representatividade adequada, que exprime um conjunto de fatores que demonstrariam concretamente o juiz, durante todo o curso do processo, ser o autor pessoa idônea, que irá despender eficazmente todos os esforços necessários para a defesa dos interesses das pessoas ausentes do processo. Por outro lado, aquela autorização interna da associação é apenas requisito abstrato para que seja plenamente satisfeita a legitimidade extraordinária em cada caso, não significando que a entidade irá realmente defender de forma adequada os interesses dos substituídos.

Na mesma toada, Eurico Ferraresi (2009, p. 113) aduz:

A representatividade adequada é um atributo da legitimidade. Por esse motivo, a avaliação da representatividade do legitimado coletivo não pode ser realizada dissociada da legitimidade. [...] A aferição da representatividade pode ser feita por dois critérios: a) pela lei ou b) pelo juiz. Ou se possibilita ao juiz a faculdade de dizer, caso a caso, se aquele que está litigando em nome da classe está agindo corretamente, atuando em defesa da classe; ou se estabelece, previamente, o rol de legitimados ativos no texto legal e se lhes atribui uma presunção legal de "qualidade".

No que concerne às entidades sindicais, a pertinência temática se extrai da dicção do art. $8^{\circ}$, III, da $\mathrm{CF} / 88$. Saliente-se que esta se refere ao campo de atuação primária dos sindicatos, podendo ser efetivada a defesa de direitos trabalhistas ainda que em face de outra categoria. Qualquer sindicato poderia efetivar a tutela de direitos para o combate ao trabalho escravo, vez que se relaciona a defesa da ordem jurídico-trabalhista, quer de forma direta, indireta ou conexa a sua categoria (SANTOS, 2014, p. 280).

Embora haja dissenso doutrinário quanto à possibilidade de, no Brasil, haver controle judicial da representatividade adequada, a posição dominante afirma pela inexistência deste controle. Segundo Antonio Gidi (2002, p. 62):

De acordo com a posição dominante no Brasil, não há controle judicial da adequação do representante nas ações coletivas. Essa era a posição, por exemplo, de Ada Pellegrini Grinover e também de Pedro Dinamarco. Nelson Nery Junior e Arruda Alvim vão além, e dizem que o juiz está proibido de 
avaliar a adequação do representante. Portanto, basta que o represente do grupo seja um dos entes legitimados pelo art. 82 do CPC (ou art. $5^{\circ}$, da LACP), para que ele possa livremente representar os interesses do grupo em juízo. Assim, por mais clara que seja a incompetência ou negligência do representante do grupo durante o desenrolar do processo coletivo, o juiz está obrigado a aceitar a situação previamente e a proferir sentença contrária aos legítimos interesses do grupo.

O argumento utilizado para fundamentar essa impossibilidade é o sistema diferenciado da coisa julgada nas ações coletivas, que se estabelece secundum eventus probationis - de acordo com a (in)suficiência das provas da demanda - e secundim eventus litis - de acordo com o resultado da lide, não podendo a coisa julgada na ação coletiva prejudicar os titulares materiais do direito.

Entretanto, para Gidi (2002, p. 62-63) este argumento não deve prosperar vez que se a sentença for exarada com suficiente material probatório, fará coisa julgada e impedirá a propositura de nova demanda coletiva para tratar daquele objeto. Ainda que os membros individuais possam propor ação individual em busca de seu direito ou interesse, uma atuação negligente de um ente coletivo impossibilitará a repropositura da demanda em prejuízo da coletividade.

O autor defende ainda a possibilidade de análise judicial vez que o limite temporal da pré-constituição não constitui qualquer garantia de representatividade adequada, devendo haver análise do caso concreto.

\section{OBSTÁCUlos PARA A EFETIVIDAdE DA TUTELA DE DIREITOS TRANSINDIVIDUAIS POR ENTIDADES SINDICAIS}

Ainda que o microssistema processual de tutela coletiva exija a adaptação das regras da tutela atomizada ao processo molecularizado, aplicando-se atualmente o denominado devido processo social, verificam-se diversos obstáculos à efetiva tutela de direitos metaindividuais, especificamente por intermédio das entidades sindicais brasileiras.

A Constituição da República de 1988 conferiu às associações profissionais ou sindicais a defesa dos direitos e interesses individuais e coletivos da categoria, tanto em questões judiciais, quanto administrativas (art. 8, III).

No entanto, verifica-se, na prática, um descompasso entre o número de sindicatos existentes no país - que conta aproximadamente com 5.307 (cinco mil trezentos e sete) 
unidades segundo o Portal de Informações sobre Relações do Trabalho instituído pelo Ministério do Trabalho - e o número de demandas coletivas ajuizadas por essas entidades. Levar-se-á em consideração diversos obstáculos para a efetiva atuação sindical, a serem analisadas nos subtópicos a seguir.

\subsection{Obstáculos globais e locais - da consolidação do capitalismo aos resquícios de um modelo corporativista}

Historicamente, o movimento sindicalista surgiu com a revolução industrial, período no qual trabalhadores, cientes da força que possuíam coletivamente, sentiram a necessidade de se reunir para reivindicar melhores condições laborais.

A implementação do modelo sindical brasileiro foi realizada nas décadas de 1930 e 1940 durante o governo de Getúlio Vargas, marcado inicialmente por grande intervenção estatal nas questões sociais. Foi com o advento da Constituição de 1934 que, formalmente, restou conferida maior liberdade e autonomia sindical, cessada pelo estado de sítio de 1935 e posterior Constituição de 1937 que possuía um viés eminentemente autoritário.

Entre períodos de progresso - demarcado pela criação do Ministério do Trabalho, Indústria e Comércio, a criação da estrutura sindical pelo Decreto 19.770/1931 e de diversos diplomas regulamentadores, como relativo ao trabalho feminino (Decreto 21.471/32) e à limitação da jornada à oito horas diárias aos comerciários e industriários (Decreto 21.364 e 21.175 de 1931) - e de retrocesso, verificado em um modelo corporativista e autocrático da época, foi criada a Consolidação das Leis do Trabalho (DELGADO, 2016, p. 1503-1506).

A efetiva democratização do modelo sindical e da tutela coletiva ocorreu, no entanto, apenas com o advento da Constituição de 1988 que passou a impedir qualquer intervenção estatal na atuação das entidades sindicais (art. $8^{\circ}$ ). Aponta-se ainda um efetivo avanço no que concerne à garantia de direitos sociais, elencados em capítulo próprio localizado no título dos direitos e garantias fundamentais.

A experiência vivenciada nas lutas operárias no continente europeu assumiu especial importância quando da imigração para o Brasil, resultando em reflexos no sindicalismo brasileiro até os dias atuais.

Diferentemente do sindicalismo daquele continente, no Brasil suas bases não resultaram de uma organização da classe e surgimento de uma consciência coletiva dos 
trabalhadores, mas de um modelo previamente utilizado e implementado nos moldes existentes na Europa. A essência do sindicalismo brasileiro é diverso do modelo ideal de consciência coletiva para a luta de classes e implementação de entidades sindicais.

A este fato, cumula-se a existência de sérias contradições no ordenamento jurídico, comprometendo o projeto constitucional democrático, inclusivo e de melhoria da condição social dos trabalhadores. Aponta-se a título exemplificativo o enquadramento sindical por categorias, respeitada a unicidade sindical (art. $8^{\circ}$, I e II, CF); a contribuição sindical obrigatória, de origem legal (Art. $8^{\circ}, \mathrm{IV}$, in fine, $\mathrm{CF}$ ) e o amplo poder normativo da justiça do trabalho (Art. 114, CF) (DELGADO, 2016, p. 1510).

O histórico do sindicalismo, as alterações vivenciadas no mundo do trabalho nos últimos anos e a lógica da estrutura corporativista que permanece até os dias atuais justifica crise de representatividade existente na maioria dos sindicatos instalados no Brasil.

Em uma perspectiva global, Márcio Túlio Viana aponta que a crise do sindicalismo se inicia pela própria globalização, passando pela reestruturação produtiva, terminando em uma ideologia neoliberal (2004, p. 54). Segundo o autor, os problemas do sindicalismo não se resumem à herança de Vargas, mas possui uma abrangência global e estrutural: o novo modelo econômico é incompatível com o sindicalismo, sendo que a empresa, ao externalizar os custos, passa a cindir a própria classe trabalhadora e com a onda flexibilizadora de direitos trabalhistas, o sindicato vai se tornando um ente de resposta e não de ataque. Faltando espaço onde possa negociar para cima, o sindicato ajuda a criar artificialmente novo espaço - para baixo - onde possa se movimentar (2004, p. 56-57). Complementa:

Do ponto de vista econômico, o sindicato sofre os efeitos de um novo modo de organizar a produção que, pouco a pouco: transforma a grande fábrica, na qual a solidariedade fermentava, numa empresa quase deserta, ou, no limite, em simples gerenciadora de uma vasta rede que envolve tanto a economia formal quanto a informal; por isso mesmo, quebra em pedaços o coletivo operário, não só em termos físicos, mas também psicológicos; usa a automação não para criar tempo livre, mas para libertar-se, de forma crescente, da necessidade de mão-de-obra; transforma parte dos trabalhadores que restam em autônomos, cooperados e estagiários, alguns reais e outros falsos, todos desprotegidos, cujos interesses não convergem mas concorrem - com os dos empregados formais [...]; transforma a empresa imóvel em móvel, permitindo-lhe sediar-se onde os sindicatos são mais frágeis [...]; oferece ao sindicato, como espaço residual de manobra, a possibilidade de negociar com os governos e com as grandes corporações o próprio processo de precarização, jogando com a perspectiva teórica de reduzi-la, mas ajudando, na prática, a legitimá-la[...] (2004, p. 55). 
De fato trata-se de alterações estruturais no mundo do trabalho que resultam em impactos no sindicalismo brasileiro, porém, superando todas essas modificações, fato é que as entidades sindicais se proliferaram de maneira célere, havendo atualmente milhares de entidades registradas no Ministério do Trabalho.

Assim, o foco se volta à estruturação constitucional do regime sindical, assoberbada de resquícios corporativistas da era Vargas.

Inicialmente aponta-se o princípio da unicidade sindical previsto no art. $8^{\circ}$, II da $\mathrm{CF} / 88$, que estabelece a vedação da criação de uma mais de uma organização sindical representativa da categoria profissional ou econômica na mesma base territorial, que não poderá ser inferior à área de um município.

Em primeiro lugar verifica-se a incompatibilidade deste preceito com o modelo de liberdade sindical preconizado pela Organização Internacional o Trabalho (OIT), agência especializada da ONU. Segundo a organização, confere-se aos indivíduos o direito a sindicalização livre, a autonomia e a pluralidade sindical, impossibilitando qualquer intervenção do estado na criação, organização e nas atividades dos sindicatos. Nestes termos, Convenções 98 e 87 da OIT.

Aponta Cláudio Santos da Silva (2011, p. 150, apud SIQUEIRA NETO, 2000, p. 90):

$\mathrm{O}$ art. $3^{\circ}$ da Convenção n. 87 assegura às organizações de trabalhadores e de entidades patronais o direito de elaborar os seus estatutos e regulamentos administrativos, de eleger livremente os seus representantes, organizar a sua gestão e a sua atividade e formular o seu programa de ação. É a denominada autonomia sindical, em que o direito de liberdade sindical é visto pelo aspecto coletivo e organizativo (SIQUEIRA NETO, 2000, p. 90). As autoridades públicas devem abster-se de qualquer intervenção susceptível de limitar esse direito ou de entravar o seu exercício legal.

Justamente diante desta incompatibilidade sistêmica que o Brasil não é signatário da Convenção 87 da OIT, mantendo-se a unicidade sindical no país.

Em segundo lugar, este modelo que limita a criação sindical resultou na pulverização de entidades, havendo a especificação demasiada de sindicatos quanto às atividades exercidas, bem como a criação de entidades pequenas, representativas de um município com estreita faixa territorial e pouca densidade populacional. 
As distorções do sistema sindical tornaram-se mais graves. Como não há mais controle administrativo estatal, os sindicatos passaram a se dividir irrefreadamente, propiciando o surgimento de situações grotescas, do ponto de vista representativo. Categorias representadas por vários sindicatos, todos eles especializados, digladiando-se por representação formal dos trabalhadores no país. Alimentou-se o baixo índice de sindicalização e favoreceu-se a existência de sindicatos pequenos, ao invés de entes sólidos e largamente representativos (DELGADO, 2011, p. 59), contribuindo para a crise de representatividade existente no país.

Outro ponto que contribuiu para esta crise é a estabilidade provisória de dirigentes sindicais, possibilitando-se a reeleição de dirigentes indeterminadas vezes, o que fez com que alguns deles assumissem a posição por décadas, fazendo do sindicato seu principal meio de vida e de sobrevivência.

De fato a estabilidade deve existir para evitar retaliações empresariais diante das atividades exercidas, que não raras às vezes contrariam os interesses do empregador. Com a finalidade de impedir a existência de dezenas de dirigentes sindicais dotados de estabilidade, o Tribunal Superior do Trabalho limitou seu número a sete dirigentes, por intermédio da Súmula 369, item III.

Entretanto, manteve-se a perpetuação de dirigentes sindicais no poder os quais eram beneficiados pelas contribuições compulsórias recolhidas obrigatoriamente por toda a categoria.

\subsection{Obstáculos Financeiros}

O financiamento do modelo sindical brasileiro era realizado preponderantemente pela contribuição sindical descontada compulsoriamente de todos os membros da categoria, com fundamento no art. 8, VI, da CF/88 e art. 578 e seguintes da CLT. Denota-se que o exercício da profissão, no caso dos trabalhadores e o estabelecimento de uma empresa, no caso dos empregadores, constituía fato gerador desta contribuição, que visava financiar o sistema sindical no Brasil.

O desconto era efetivado no importe de um dia de trabalho para os empregados, qualquer que fosse a forma de sua remuneração (art. 580, CLT), sobre uma importância proporcional ao capital social da firma ou empresa, registrado na Junta Comercial, conforme tabela progressiva prevista no art. 580, III, CLT, para todos os empregadores, bem como de 
acordo com uma tabela progressiva aos profissionais autônomos e aos profissionais liberais, na forma do parágrafo $4^{\circ}$ do referido artigo.

Em complementariedade, poderiam os sindicatos instituir, em assembleia destinada para este fim, outras modalidades de receitas sindicais como a contribuição confederativa (art. 8, VI, CF/88), contribuição assistencial e mensalidades sindicais. Com vistas à prevalência do princípio da liberdade sindical, estas poderiam ser cobradas exclusivamente daqueles filiados ao respectivo sindicato. Nestes termos, Orientação jurisprudencial $\mathrm{n}^{\mathrm{o}} 17$ e Precedente Normativo $\mathrm{n}^{\circ} 119$, da Seção de Dissídios Coletivos, súmula vinculante 40 do Supremo Tribunal Federal e ARE 1.018.459.

Assim, o financiamento sindical ocorria preponderante pela contribuição sindical compulsória, receita certa recolhida por todos os trabalhadores, filiados ou não ao sindicato, e pelas contribuições instituídas em assembleia geral ou em convenções e acordos coletivos de trabalho, descontadas apenas de filiados.

Este consiste em mais um resquício do modelo corporativo implementado na era Vargas e que acentuou a crise de representatividade das entidades sindicais. Muitas delas eram constituídas apenas com a finalidade de constituição de renda aos dirigentes sindicais, sem qualquer atuação concreta e efetiva em prol da categoria.

Soma-se a isso o fato de haver um desconhecimento, por parte da maioria dos trabalhadores brasileiros, sobre a existência ou finalidade dos sindicatos, resultando na ausência de qualquer cobrança por parte da própria classe trabalhadora. Por este motivo, o número de filiados é exíguo se comparado ao número de trabalhadores da categoria e ao número de entidades sindicais existentes no país.

No entanto, a Lei 13.467/2017 (Reforma Trabalhista) veio alterar esta realidade, instituindo a facultatividade no recolhimento da contribuição sindical compulsória, a ser descontada apenas mediante autorização. Segundo Luciano Martinez (2018, p. 172):

A despeito do princípio da liberdade de sindicalização previsto no Texto Constitucional (vide o art. 8.o, VII), a contribuição sindical foi exigida de

\footnotetext{
${ }^{4}$ Recurso Extraordinário. Repercussão Geral. 2. Acordos e convenções coletivas de trabalho. Imposição de contribuições assistenciais compulsórias descontadas de empregados não filiados ao sindicato respectivo. Impossibilidade. Natureza não tributária da contribuição. Violação ao princípio da legalidade tributária. Precedentes. 3. Recurso extraordinário não provido. Reafirmação de jurisprudência da Corte. (ARE 1018459 RG, Relator(a): Min. GILMAR MENDES, julgado em 23/02/2017, PROCESSO ELETRÔNICO REPERCUSSÃO GERAL MÉRITO DJe-046 DIVULG 09-03-2017 PUBLIC 10-03-2017.
} 
associados e de não associados até o advento da reforma trabalhista de 2017. O STF, apesar de reconhecer que a manutenção dessa base de custeio sindical era um resquício do modelo corporativista que teimava em permanecer, manteve firme posicionamento no sentido de que ela foi recepcionada pela ordem constitucional ${ }^{5}$.

Em complementariedade, foi editada em $1^{\circ}$ de março de 2019 a Medida Provisória $n$. 873 que alterou a redação dos arts. 545, 578, 579, 579-A e 582 da CLT, reforçando a necessidade de autorização prévia, voluntária, individual e expressa por parte do trabalhador, adotando a modalidade de pagamento por intermédio de boleto bancário ou equivalente eletrônico, sendo encaminhado diretamente à residência do empregado (Art. 582, CLT). Apenas na hipótese de impossibilidade de recebimento, o boleto seria encaminhado à sede da empresa.

A referidas alterações recentes realizadas na legislação extinguiram, de forma abrupta, o principal meio de financiamento dos sindicatos. Denota-se que há entendimento doutrinário encampado pelo Ministério Público do Trabalho, que defende a inconstitucionalidade e inconvencionalidade da alteração do modo como foi realizada, proporcionando um desequilíbrio nas bases do sindicalismo brasileiro.

Referido órgão aponta ainda pela necessidade de implementação, em sede de negociação coletiva, de uma contribuição a ser cobrada de todos os membros da categoria com vistas à mantença do custeio sindical, nos termos do Enunciado n. 38 da $2^{\mathrm{a}}$ Jornada de Direito Material e Processual do Trabalho, que adverte:

I - É lícita a autorização coletiva prévia e expressa para o desconto das contribuições sindical e assistencial, mediante assembleia geral, nos termos do estatuto, se obtida mediante convocação de toda a categoria representada especificamente para esse fim, independentemente de associação e sindicalização.

\footnotetext{
${ }^{5}$ (...) Sob o ângulo material, o STF afirmou que a Constituição assegura a livre associação profissional ou sindical, de modo que ninguém é obrigado a filiar-se ou a manter-se filiado a sindicato (art. 8o, $\mathrm{V}$, da CF/88). $O$ princípio constitucional da liberdade sindical garante tanto ao trabalhador quanto ao empregador a liberdade de se associar a uma organização sindical, passando a contribuir voluntariamente com essa representação. Não há nenhum comando na Constituição Federal determinando que a contribuição sindical é compulsória. Não se pode admitir que o texto constitucional, de um lado, consagre a liberdade de associação, sindicalização e expressão (art. 5o, IV e XVII, e art. 8ㅇ) e, de outro, imponha uma contribuição compulsória a todos os integrantes das categorias econômicas e profissionais. STF. Plenário. ADI 5794/DF, Rel. Min. Edson Fachin, red. p/ o ac. Min. Luiz Fux, julgado em 29/6/2018 (Info 908).
} 
II - A decisão da Assembleia Geral será obrigatória para toda a categoria, no caso das convenções coletivas, ou para todos os empregados das empresas signatárias do acordo coletivo de trabalho.

III - O poder de controle do empregador sobre o desconto da contribuição sindical é incompatível com o caput do art. 80 da Constituição Federal e com o art. 1o da Convenção 98 da OIT, por violar os princípios da liberdade e da autonomia sindical e da coibição aos atos antissindicais.

Entretanto, a Medida Provisória n. 873 veio rechaçar qualquer prática neste sentido, sendo imperioso, neste momento, a reinvenção das entidades sindicais para a consecução de filiados visando angariar fundos para sua mantença e sobrevivência.

\section{CONSIDERAÇÕES FINAIS}

Os sindicatos constituem um dos entes legitimados pelo ordenamento jurídico para a tutela de direitos metaindividuais especificamente no âmbito do direito trabalhista. Trata-se de ente que visa proporcionar, além da melhoria da condição social dos trabalhadores um efetivo acesso à justiça a toda a classe, vez que, além de outros benefícios, promove a despersonalização da demanda individual, necessária à judicialização de litígios quando vigente o vínculo empregatício.

Entretanto, a tutela coletiva no âmbito sindical esbarra em diversos obstáculos presentes desde a criação dessas entidades. Inicialmente se verifica que as entidades sindicais foram criadas no Brasil com a imigração europeia que trouxe uma larga experiência na temática, vez que a revolução industrial e o avanço do capitalismo se faziam presentes em momentos pretéritos naquele continente. Seu surgimento não decorreu de uma consciência coletiva por parte dos trabalhadores, mas de um modelo previamente utilizado e implementado nos moldes europeus, constituindo um dos motivos do enfraquecimento de muitas entidades no Brasil.

Apontam-se também fatores globais que propiciam, por natureza, o enfraquecimento dos sindicatos como a globalização e a reestruturação produtiva, a terceirização de setores, a economia informal e a reinvenção dos sindicatos com a onda de flexibilização de direitos.

Contribui também para a referida crise contradições no ordenamento jurídico que manteve diversos resquícios de um modelo corporativista implementado na era Vargas, como a unicidade sindical, que resultou na pulverização de sindicatos, e a contribuição sindical 
compulsória, vigente durante décadas que amparou a criação de entidades descomprometidas com sua finalidade, mas implementadas como maneira de angariar recursos tributários, exigíveis de todos das categorias.

A ausência de uma entidade sindical sólida e comprometida com sua finalidade precípua de defesa dos direitos individuais e metaindividuais da categoria resulta em extremo prejuízo à melhoria da condição social desses trabalhadores, bem como ao acesso à justiça de toda a classe, que não encontra no ente sindical, pessoa jurídica mais próxima das peculiaridades de sua classe, uma efetiva atuação em prol de direitos coletivos, difusos e individuais homogêneos.

Vivenciamos períodos de flexibilização de direitos em que a reorganização sindical é extremamente importante com vistas a maior mobilidade e efetivação de direitos fundamentais, especialmente da dignidade da pessoa humana.

\section{REFERÊNCIAS}

ARMELIN, Donaldo. Legitimidade para agir no direito processual civil brasileiro. São Paulo: RT, 1979.

CAPPELlETTI, Mauro; GARTH, Bryant. Acesso à Justiça. Trad. Ellen Gracie Northfleet. Porto Alegre: Fabris, 1988.

DELGADO, Mauricio Godinho. Curso de direito do trabalho. 15. ed. São Paulo: LTr, 2016.

DELGADO, Mauricio Godinho. Sindicato no Brasil: Problemas e Perspectivas. In:

PEREIRA, Ricardo José Macedo de Britto; PORTO, Lorena Vasconcelos (Orgs). Temas de direito sindical: homenagem a José Cláudio Monteiro de Brito Filho. São Paulo: LTr, 2011, p. 54-66.

DIDIER JR., Fredie. Curso de direito processual civil: introdução ao direito processual civil, parte geral e processo de conhecimento I. 17. ed. - Salvador: Ed. Jus Podivm, 2015.

DINAMARCO, Pedro da Silva. Ação civil pública. São Paulo: Saraiva, 2001.

FERRARESI, Eurico. Ação popular, ação civil pública e mandado de segurança coletivo: instrumentos processuais coletivos . 1. ed. Rio de Janeiro: Forense, 2009.

GIDI, Antonio. A representação adequada nas ações coletivas brasileiras: uma proposta.

In WANBIER, Tereza Arruda Alvim (coord). Revista de Processo, 2002.

MARTINEZ, Luciano. Reforma trabalhista - entenda o que mudou: CLT comparada e comentada. 2. ed. São Paulo: Saraiva Educação, 2018. 
MINISTÉRIO DO TRABALHO. Portal de Informações sobre Relações do Trabalho: Democratização das relações do trabalho, Acesso à informação, Disseminação de Conhecimento e Aprimoramento da Gestão Pública. Disponível em:

$<$ http://relacoesdotrabalho.mte.gov.br/pentaho/api/repos/:public:SRT:srt_principal1.xaction/g eneratedContent>. Acesso em 20 mar. 2019.

MINISTÉRIO PÚBLICO DO TRABALHO. Nota técnica n. $\mathbf{1}^{\mathbf{0}}$, de 27 de abril de 2018. Disponível em: <http://portal.mpt.mp.br/wps/wcm/connect/portal_mpt/de971da2-2452-4c198ee9-84fe10038a02/Nota+Tecnica_n_1-2018_CONALIS-MPT-Contribuicao+Sindical-2704-2018-

assinada.pdf?MOD=AJPERES\&CONVERT_TO=url\&CACHEID=ROOTWORKSPACE.Z1 8_395C1BO0K89D40AM2L613R2000-de971da2-2452-4c19-8ee9-84fe10038a02msZdHpk>. Acesso em 20 mar. 2019.

RAMOS, Glauco Gumerato. Realidade e perspectivas da assistência jurídica aos necessitados no Brasil. São Paulo: Fundação Konrad Adenauer, 2000..

SANTOS, Enoque Ribeiro dos. Processo coletivo do trabalho. 2. ed., rev., atual. e ampl. Rio de Janeiro: Forense, 2018.

SANTOS, Ronaldo Lima dos. Sindicatos e ações coletivas: acesso à justiça, jurisdição coletiva e tutela dos interesses difusos, coletivos e individuais homogêneos. 4. ed. rev. e ampl. São Paulo: LTr, 2014.

SILVA, Cláudio Santos da. A liberdade sindical no direito internacional do trabalho: reflexões orientadas pela Convenção n. 87 da OIT. São Paulo: LTr, 2011

VIANA, Márcio Túlio. A reforma sindical, entre o consenso e o dissenso. In: Justiça do Trabalho. Porto Alegre: HS Editora, ano 21, n. 249, 2004. 